\title{
Evaluation of Ovarian Cancer Care at the End of Life in a Single Tertiary Hospital
}

\author{
Hanna Sallinen ${ }^{1}$, Vivi Rintanen ${ }^{1,2}$, Leea Keski-Nisula ${ }^{1,2}$, Maarit Anttila1 \\ ${ }^{1}$ Department of Gynecology and Obstetrics, Kuopio University Hospital, Kuopio, Finland \\ ${ }^{2}$ Department of Health Sciences, Clinical Medicine, University of Eastern Finland, Kuopio, Finland \\ Email: *hanna.sallinen@kuh.fi
}

How to cite this paper: Sallinen, H., Rintanen, V., Keski-Nisula, L. and Anttila, M. (2021) Evaluation of Ovarian Cancer Care at the End of Life in a Single Tertiary Hospital. Journal of Cancer Therapy, 12, 86-96. https://doi.org/10.4236/jct.2021.122010

Received: January 11, 2021

Accepted: February 20, 2021

Published: February 23, 2021

Copyright (c) 2021 by author(s) and Scientific Research Publishing Inc. This work is licensed under the Creative Commons Attribution International License (CC BY 4.0).

http://creativecommons.org/licenses/by/4.0/

(c) (i) Open Access

\begin{abstract}
Aim: Fundamentally, aggressive care is considered to be avoided for the patients at the end of life. However, this is not always adhered in real-world practice. We attempted to determine whether, and if so how, the aggressive care is made for patients with ovarian cancer during the last month prior death. Methods. Enrolled were a total of 104 patients with ovarian cancer (including fallopian tube or primary peritoneal cancer), who were treated in Kuopio University Hospital in Finland during 2009-2014. The aggressive care was defined according to the standards outlined by the National Quality Forum; shortly, chemotherapy, emergency-room/intensive-care visit/admission, hospital admission, and death in hospital. Results. Two thirds of patients (67\%) had received at least one form of aggressive care during the last month of their lives. Especially, admission in hospital in the last 30 days of life was the most common form of aggressive cancer care. Younger patients $(<72$ years) received significantly more often aggressive care than the older patients $(80 \%$ vs $43 \%, p=0.004)$. Those women that underwent end-of-life discussions earlier than one month prior to death had significantly less aggressive care than those women that had discussions during the last month (48\% vs. $90 \%, \mathrm{p}=0.001)$. Conclusions. Ovarian cancer patients received commonly at least one form of aggressive care at the end of their lives. More efforts should be taken to improve the quality of palliative and end-of-life care.
\end{abstract}

\section{Keywords}

Aggressive Care, Ovarian Cancer, End Of Life, Palliative Care

\section{Introduction}

Ovarian cancer accounts for $5 \%$ of cancer deaths among women, causing more deaths than any other gynecological cancer. The average 5-year overall survival 
rate in Europe is $36 \%$ [1]. The standard primary treatment for ovarian cancer is cytoreductive surgery and a platinum-based combination therapy, mostly with paclitaxel [2]. Despite responding to the initial treatment, ovarian cancer is known to relapse in most patients and eventually leads to death [3]. Following recurrence, the patients are often treated with multiple lines of chemotherapy. Nowadays, women may have had even up to ten different lines of chemotherapy before eventual death [4].

One of the challenges in treating patients with advanced ovarian cancer is to find a balance between heavy treatments of cancer and still maintain the best possible quality of life. Palliative chemotherapy might reduce cancer-related symptoms, but on the other hand, can also cause notable side effects [5]. Decision of proceeding to palliative cancer care might be difficult to some patients and their families, but also sometimes to the physicians. Assessing the quality of life is difficult since it cannot be objectively measured. The National Quality Forum has outlined standards of aggressive care at the end of life in cancer patients [6]: 1) chemotherapy within the last 14 days of life, 2) more than one emergency room visit within the last 30 days of life, 3 ) more than one hospital admission in the last 30 days of life, 4) more than 14 days spent admitted to the hospital in the last 30 days of life and 5) intensive care unit admission in the last 30 days of life and 6) death in hospital. Several physicians have used these standards to describe aggressive treatment at the end of life [7] [8] [9]. There is growing evidence that aggressive care at the end of life may not be associated with any improved survival [10] [11]. Furthermore, it might even complicate the success of palliative care and self-preparation to the forthcoming death.

The aim of this study was to describe more precisely how ovarian cancer patients were treated during the last 30 days of their lives in relation to the aggressive care in our institution. We also studied whether there were differences in clinical parameters between patients with and without aggressive treatments. To our knowledge, this is the first study to describe aggressive care in Scandinavian patients with ovarian cancer during the last month of their lives.

\section{Methods}

This retrospective study investigated patients who had been treated due to ovarian, fallopian tube or primary peritoneal cancer between years 2009-2014 in Kuopio University Hospital. A patient was selected from the medical register of our hospital if she had received primary treatment for her cancer, and if she had also been followed up in our institution. All patients were deceased and deaths were related to advanced underlying cancer. A total of 104 patients were included in this cohort. The medical files of these patients were retrospectively reviewed. Data were abstracted and entered to a computerized database. The following information regarding the standards outlined by the National Quality Forum was collected: chemotherapy within the last 14 days of life, more than one emergency room visit within the last 30 days of life, more than one hospital admission in the 
last 30 days of life, more than 14 days spent admitted to the hospital in the last 30 days of life, intensive care unit admission during the last 30 days of life and death in hospital. The occurrence of any of these events indicates aggressive medical care and a lower incidence represents better end-of-life care.

Other data collected from medical files included histology, stage and grade of cancer, time of diagnosis, age, time and location of death, a number of relapses, a number and type of chemotherapy lines, presence and date of end-of life discussion and date of issuing "do not attempt resuscitation" (DNAR). End-of-life discussion was identified if in medical files was reported that physician and patient discussed and ended active anti-cancer treatment, referral to the hospice was made or DNAR was issued.

The term of recurrence was defined clinically, i.e. physical evidence upon imaging or examination and/or a rise in CA-125 marker evaluated by physicians. Not responding to treatment or progression during treatment was interpreted as treatment-resistant disease, not relapse. Overall survival (OS) was calculated from the day of diagnosis to death. Progression free survival (PFS) was calculated from the day of diagnosis to the first relapse and then from one relapse to the subsequent one or death.

Descriptive statistics were used to characterize the study cohort as median with range or frequency and percentage. Kruskal-Wallis test and Mann Whitney U-test were used when appropriate to analyze continuous variables. A chi-squared test was used in analysing frequency tables. Survival analyses were based on Kaplan-Meier method and log rank-test was used to analyse OS and PFS. Statistically significant results were considered with a value of $p<0.05$. SPSS for Windows (version 27, IBM Corp., Armonk, N.Y., USA) was used for statistical analyses.

According to the Finnish legislation, no ethical approval from official ethics committee or consent from the patient is mandatory for a register-based study. The Finnish law (Medical Research Act 1999/488, 2004/295, 2010/794) states medical research requiring the approval of an appropriate ethics committee as following: research involving intervention in the integrity of a person, human embryo or human foetus for the purpose of increasing knowledge or the nature of diseases in general. Register based scientific research is stated also in the Act on the Openness of Government Activities (621/1999) and Personal Data Act (523/1999). According to these Acts the administrative approval by the participating hospital is adequate which in this case has been received.

\section{Results}

\subsection{Characteristics of the Patients}

A total of 104 patients were included in this study. Most of them $(85 \%, \mathrm{n}=88)$ had advanced stage III or IV disease at the time of diagnosis. A majority of the patients $(80 \%, n=77)$ had underwent primary or secondary cytoreductive surgery. Details of the characteristics of the patients are summarized in Table 1. 
Table 1. Characteristics of the patients, $\mathrm{n}=104$.

\begin{tabular}{lr}
\multicolumn{1}{c}{ Variable } & $\boldsymbol{n}(\%)$ \\
\hline Age at the time of diagnosis, median (range) & $68(28-$ \\
Histology & $76(73)$ \\
Serous $^{\dagger}$ & $7(7)$ \\
Mucinous & $5(5)$ \\
Endometroid & $2(2)$ \\
Clear cell & $8(7)$ \\
Histology unknown & $6(6)$ \\
Other & \\
Stage & $7(7)$ \\
I & $2(2)$ \\
II & $50(48)$ \\
III & $38(36)$ \\
IV & $7(7)$ \\
Not documented &
\end{tabular}

Grade

$\begin{array}{ll}\text { High grade } & 80(77)\end{array}$

Low grade $4(4)$

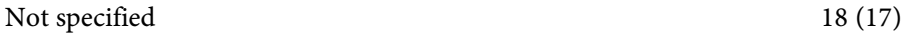

Diagnostics

Primary cytoreductive surgery $63(61)$

Secondary cytoreductive surgery 17 (16)

Diagnostic laparoscopy $3(3)$

Biopsy $\quad 8(8)$

Imaging $12(12)$

Not documented $1(1)$

$\begin{array}{ll}\text { Operated patients } & 80(77)\end{array}$

Residual tumor (cm)

$\begin{array}{lc}\text { none } & 26(32) \\ <1 & 11(14) \\ \geq 1 & 37(46) \\ \text { Not documented } & 6(8)\end{array}$

Tumor recurrence

Recurrent $76(73)$

Not recurrent $17(16)$

Resistant to treatment $11(11)$

End-of-life discussion $\quad 89$ (86)

${ }^{\dagger} 7$ (6.7\%) fallopian tube, 7 (6.7\%) peritoneal; ${ }^{\ddagger}$ Ovarian carcinosarcoma, transitional cell cancer, male differentatum and psammomacarcinoma of the ovary. 


\subsection{Aggressive Care and Follow Up}

As shown in Figure 1, two thirds of the patients $(67 \%, n=70)$ had received at least one form of aggressive care. The most common form of aggressive care was admission to the hospital in the last 30 days of life at least once $65 \%(n=68)$. Furthermore, $37 \%(n=38)$ of the patients had stayed in the hospital longer than 14 days during the last month of their lives (Figure 1).

Table 2 shows that younger patients had received significantly more often aggressive care at the end of life than the older patients (median 69 (range 35 - 90) years vs. $76(31$ - 95) years, $\mathrm{p}=0.001)$. In addition, younger patients i.e. patients $<72$ years at the time of death, received significantly more often aggressive care at the end of life than the older patients $(80 \%$ vs $43 \%, \mathrm{p}=0.004)$. Other clinical parameters such as tumor histology, stage or grade of the disease or the amount of residual tumor in primary surgery were not associated with aggressive care at the end of life.

Table 2. Comparison of clinical parameters of the patients between groups of aggressive care and no aggressive care.

\begin{tabular}{|c|c|c|c|}
\hline Variable & $\begin{array}{l}\text { Aggressive care } \\
\qquad \mathrm{n}=70\end{array}$ & $\begin{array}{c}\text { No aggressive care } \\
\qquad \mathrm{n}=34\end{array}$ & $p$ value \\
\hline $\mathrm{Age}^{\dagger}$ median (range) years & $69(35-90)$ & $76(31-95)$ & 0.001 \\
\hline $\mathrm{Age}^{\dagger}$ & $\mathrm{n}(\%)$ & $\mathrm{n}(\%)$ & 0.004 \\
\hline$<72$ years & $42(60)$ & $10(29)$ & \\
\hline$\geq 72$ years & $28(40)$ & $24(71)$ & \\
\hline Histology & & & ns \\
\hline Serous $\ddagger$ & $53(76)$ & $20(59)$ & \\
\hline Mucinous & $4(6)$ & $3(9)$ & \\
\hline Endometroid & $2(3)$ & $3(9)$ & \\
\hline Clear cell & $2(3)$ & 0 & \\
\hline Other & $9(12)$ & $5(15)$ & \\
\hline Stage & & & ns \\
\hline I & $6(9)$ & $1(3)$ & \\
\hline II & $1(1)$ & $1(3)$ & \\
\hline III & $35(50)$ & $15(44)$ & \\
\hline IV & $25(36)$ & $13(38)$ & \\
\hline End-of-life discussion & & & 0.001 \\
\hline During last 30 days before death & $36(51)$ & $4(12)$ & \\
\hline Earlier than 30 days before death & $22(31)$ & $24(71)$ & \\
\hline Not documented & $12(17)$ & $6(17)$ & \\
\hline $\begin{array}{l}\text { A number of chemotherapy lines, } \\
\text { median (range) }\end{array}$ & $4(1-14)$ & $4(1-9)$ & ns \\
\hline Overall survival, median (95\% CI) months & $27(15-37)$ & $33(23-39)$ & ns \\
\hline
\end{tabular}

${ }^{\dagger}$ at the time of death, ${ }^{*}$ includes fallopian tube and primary peritoneal cancers; ns = not significant. 


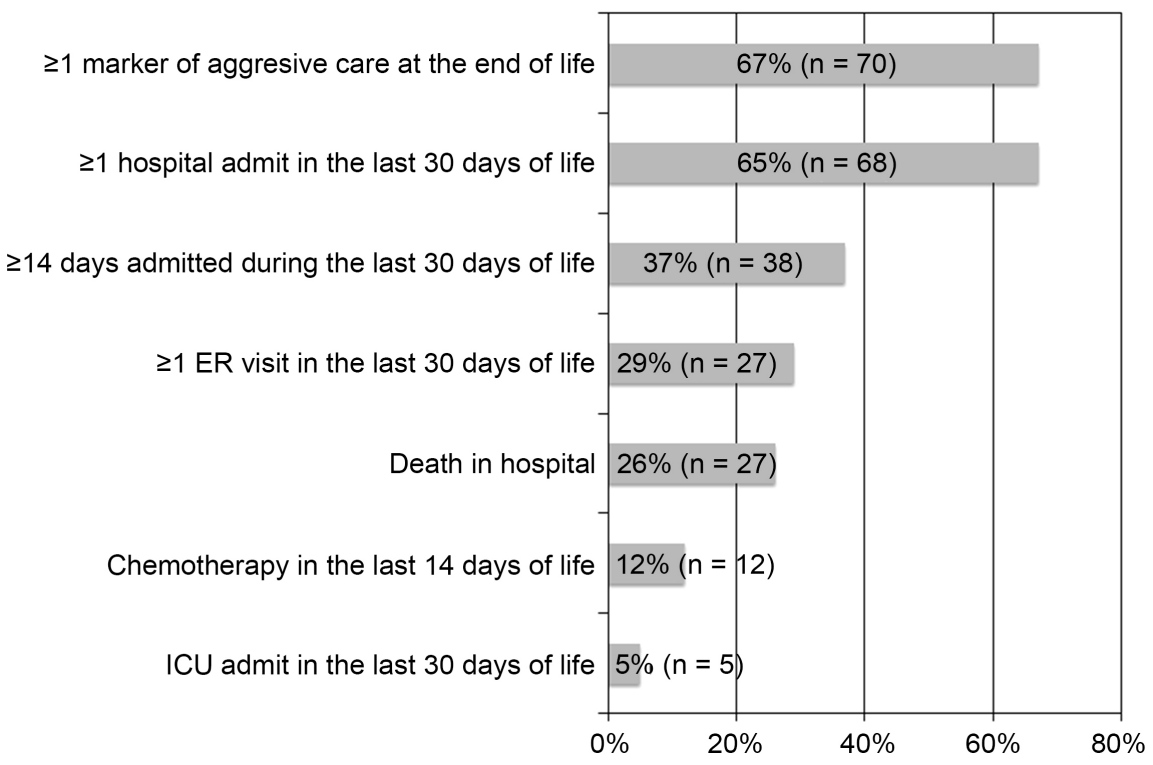

Figure 1. Percentages of patients that received aggressive care at the end of life. ER, emergency-room; ICU, intensive care unit.

The median follow-up time of the patients was 29 months (range 0 - 189 months). The median overall survival was 29 (95\% CI 22 - 36) months and median progression free survival was 13 (95\% CI 12 - 16) months. There was no significant difference in the overall survival between the group of patients that received at least one form of aggressive care and compared to those who did not receive aggressive care.

\subsection{End-of-Life Discussions and Aggressive Care}

Altogether $86 \%$ of the patients $(n=89)$ underwent end-of-life discussion with a physician prior death (Table 1). The median interval between discussion and the time of death was 37 days (mean 77 days, range 0 - 23 months). The median interval between the DNAR decision and death was 21 days (mean 53 days, range 0 - 23 months). Those women who had discussed their end-of-life discussion earlier than one month prior death, received significantly less aggressive care at the end of life than those who had underwent discussions during the last month (48\% vs. $90 \%, \mathrm{p}=0.001)$ (Table 2 ).

\subsection{Hospital Admissions in the Last 30 Days of Life}

During the last 30 days of life, $65 \%$ of the patients $(n=68)$ were admitted to hospital at least once. As shown in Figure 2, the most common reason for hospital admission was ascites and/or pleural effusion $(28 \%, \mathrm{n}=19)$. A total of 12 patients (18\%) suffered from infection such as pneumonia, sepsis, peritonitis, or an undetermined infection. Another 12 patients (18\%) had bowel problems, either symptoms of obstruction or complete bowel obstruction. Symptoms of advanced disease such as nausea, dyspnea, pain and weakness were reasons to hospital admission in nine patients (13\%). In addition, four patients (6\%) suffered 
from pulmonary embolism. Other reasons (17\%) for hospital admission were heart failure, stroke, neutropenia, intracranial hemorrhage, hip fracture, hydronephrosis or seizure.

\subsection{Chemotherapy Lines and Aggressive Care}

The median number of the received chemotherapy lines was four (mean 4, range 1 - 14). Of the patients, $44 \%$ received over five lines of chemotherapy (Figure 3 ). Each patient received a platinum-based regimen as the first-line regimen. The most common chemotherapeutic regimen for primary disease was a paclitaxel-carboplatin combination (74\%), followed by single-carboplatin (16\%) and a combination of docetaxel and carboplatin (6\%). In subsequent treatment lines, the distribution of chemotherapy regimens was more diverse. A number of previous chemotherapy lines at the end of life were not associated with aggressive care (Table 2).

\subsection{Location of Death}

Seventy-seven patients (74\%) were enrolled in hospice. Of them, the median time in hospice was 21 days (mean 60 days, range 0 - 23 months) prior death. The duration of hospice stay was three days or less in $12 \%$ of the patients. Twenty-seven patients (26\%) died in hospital, of them one patient in the intensive care unit, one in the emergency unit, two in the department of medical oncology, one in the department of internal medicine, one in the department of surgery and the remaining 21 patients in the inpatient ward of gynecology.
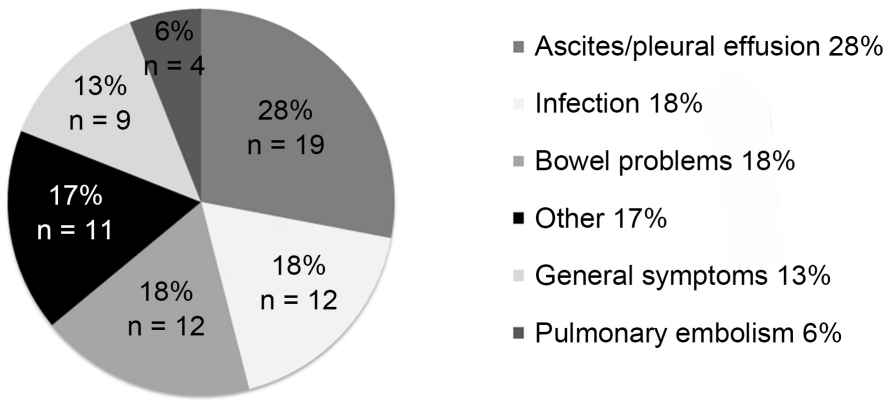

Figure 2. Reasons for hospital admissions in the last 30 days of life.

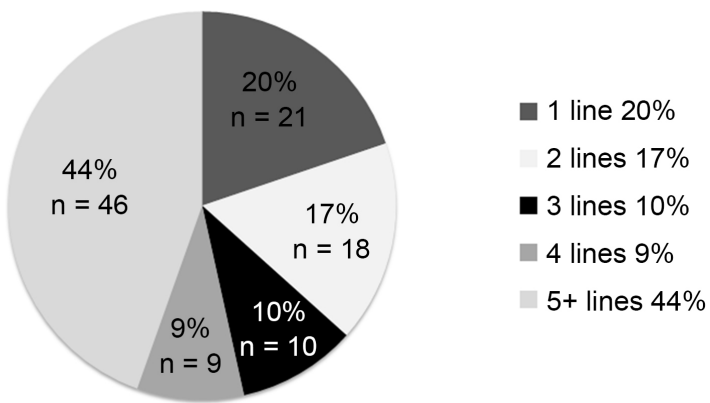

Figure 3. Percentages of the number of chemotherapy lines received before death listed from one to more than five. 


\section{Discussion}

We describe here a single tertiary center experience of end of life care in patients with ovarian, fallopian tube or primary peritoneal cancer. Those cancers are clinically similar in presentation and are treated similarly. We found that a majority of the patients receives aggressive care in the last 30 days of their lives. To date, this is the first study that evaluated the aggressiveness of care at the end of life in Scandinavian patients with ovarian cancer.

In the present study, $67 \%$ of the patients received at least one form of aggressive care according to the standards of The National Quality Forum. In our cohort, the most common form of aggressive care was more than one admission in the hospital within last 30 days before death. Unfortunately, the fourth of patients admitted to hospital in the last 30 days of life stayed in hospital for longer than two weeks. Most common reasons for admissions in our study were pleur$\mathrm{al} /$ ascites effusions, infections and bowel problems. These are similar to the reasons listed in previous studies [11] [12]. Our admission rates are slightly higher than reported in previous other studies of ovarian cancer patients [8] [9] [11]. However, two thirds of the patients were eventually enrolled in hospice care, but these enrollments often occurred only a few days or weeks prior to death. This is in line with two former studies from the USA [8] [12].

Kumar et al. [13] have reported that admittance to hospice was related to better family-reported quality of life and care in patients with advanced cancer. Specifically, patients that were in hospice for a longer period of time were more likely to for example receive optimal pain management than patients enrolled for less than three days before death [13]. Thus, we should pay attention to offer palliative hospice care for advanced ovarian cancer patients early enough. Reasons for late hospice referrals might be physician and patient related. Important patient-related factors that may have an impact on hospice referrals can include preparedness to accept the end of life or poor confidence in hospice care. It is reported that if patients were treated in comprehensive cancer centers or in high-volume centers without palliative care units, they most likely received chemotherapy near the end of life [14]. Nowadays, a palliative care unit has been opened in our institution, which might promote the adequate palliative care guidance to patients and physicians.

Half of the patients who received chemotherapy during the last 14 days of their life, also died in the hospital. Parallel to our results, a French study reported [14] that $11.3 \%$ of the patients with solid tumors received chemotherapy during the last two weeks. Although there is evidence that chemotherapy near death is not beneficial for patients, physicians are often overly optimistic about the benefits of chemotherapy [5] or overestimate survival [15]. End-of-life discussions are recommended to be held early on the disease course rather than near death to avoid aggressive care at end of life [9] [16]. Similar to a previous study of colorectal cancer [17], we noticed that patients who underwent end-of-life discussions before the last 30 days of their lives, were less likely to re- 
ceive aggressive care at the end of life.

However, serial chemotherapy lines are beneficial in selected patients with ovarian cancer [18]. Particularly in platinum resistant patients, clinicians should consider whether further chemotherapy is worthwhile or ineffective or whether it causes toxicity or reduction of the quality of life. According to the Gynecological Cancer Intergroup (GCIG) Symptom Benefit Study, measuring the health-related quality of life and using the modified Glasgow Prognostic Score could help to identify women that unlikely benefit from chemotherapy [19] [20]. To date, there is an unmet need for trials of patients that have received multiple chemotherapy lines [21].

There are several limitations in this study. Firstly, our study is retrospective and the number of patients is limited. It should also be noticed that this is a single center study and our results cannot be generalized to the other hospitals. Secondly, our data lacks the assessment of the quality of life.

\section{Conclusion}

In conclusion, we present that ovarian cancer patients receive commonly at least one form of aggressive care at the end of life. End-of-life discussions should be performed in early course of the disease to avoid unnecessary treatments. Efforts to prepare patients and their families for palliative care early enough should be taken.

\section{Funding}

This study was supported by The Finnish Medical Foundation and Kuopio University Hospital VTR grant.

\section{Conflicts of Interest}

The authors declare no conflicts of interest regarding the publication of this paper.

\section{References}

[1] Oberaigner, W., Minicozzi, P., Bielska-Lasota, M., Allemani, C., de Angelis, R., Mangone, L., et al. (2012) Survival for Ovarian Cancer in Europe: The Across-Country Variation Did Not Shrink in the Past Decade. Acta Oncologica, 51, 441-453. https://doi.org/10.3109/0284186X.2011.653437

[2] du Bois, A., Luck, H.J., Meier, W., Adams, H.P., Mobus, V., Costa, S., et al. (2003) A Randomized Clinical Trial of Cisplatin/Paclitaxel versus Carboplatin/Paclitaxel as First-Line Treatment of Ovarian Cancer. Journal of the National Cancer Institute, 95, 1320-1329. https://doi.org/10.1093/jnci/djg036

[3] Agarwal, R. and Kaye, S.B. (2003) Ovarian Cancer: Strategies for Overcoming Resistance to Chemotherapy. Nature Reviews Cancer, 3, 502-516. https://doi.org/10.1038/nrc1123

[4] Eng, K.H., Hanlon, B.M., Bradley, W.H. and Szender, J.B. (2015) Prognostic Factors Modifying the Treatment-Free Interval in Recurrent Ovarian Cancer. Gynecologic Oncology, 139, 228-235. https://doi.org/10.1016/j.ygyno.2015.09.011 
[5] Friedlander, L.M., Stockler, T.M., O’connell, T.R., Voysey, T.M., Oza, T.A., Gillies, T.K., et al. (2014) Symptom Burden and Outcomes of Patients with Platinum Resistant/Refractory Recurrent Ovarian Cancer: A Reality Check: Results of Stage 1 of the Gynecologic Cancer Intergroup Symptom Benefit Study. International Journal of Gynecological Cancer, 24, 857-864.

https://doi.org/10.1097/IGC.0000000000000147

[6] Anonymous National Voluntary Consensus Standards for Quality of Cancer Care. http://www.qualityforum.org/Publications/2009/05/National_Voluntary_Consensus _Standards_for_Quality_of_Cancer_Care.aspx

[7] Earle, C.C., Landrum, M.B., Souza, J.M., Neville, B.A., Weeks, J.C. and Ayanian, J.Z. (2008) Aggressiveness of Cancer Care near the End of Life: Is It a Quality-of-Care Issue? Journal of Clinical Oncology, 26, 3860-3866.

https://doi.org/10.1200/JCO.2007.15.8253

[8] Brown, A.J., Sun, C.C., Prescott, L.S., Taylor, J.S., Ramondetta, L.M. and Bodurka, D.C. (2014) Missed Opportunities: Patterns of Medical Care and Hospice Utilization among Ovarian Cancer Patients. Gynecologic Oncology, 135, 244-248. https://doi.org/10.1016/j.ygyno.2014.08.039

[9] Lopez-Acevedo, M., Havrilesky, L.J., Broadwater, G., Kamal, A.H., Abernethy, A.P., Berchuck, A., et al. (2013) Timing of End-of-Life Care Discussion with Performance on End-of-Life Quality Indicators in Ovarian Cancer. Gynecologic Oncology, 130, 156-161. https://doi.org/10.1016/j.ygyno.2013.04.010

[10] Temel, J.S., Greer, J., Muzikansky, A., Gallagher, E., Admane, S., Jackson, V., et al. (2010) Early Palliative Care for Patients with Metastatic Non-Small-Cell Lung Cancer. The New England Journal of Medicine, 363, 733. https://doi.org/10.1056/NEJMoa1000678

[11] Von Gruenigen, V., Daly, B., Gibbons, H., Hutchins, J. and Green, A. (2008) Indicators of Survival Duration in Ovarian Cancer and Implications for Aggressiveness of Care. Cancer, 112, 2221-2227. https://doi.org/10.1002/cncr.23391

[12] Fauci, J., Schneider, K., Walters, C., Boone, J., Whitworth, J., Killian, E., et al. (2012) Utilization of Palliative Care in Gynecologic Oncology Patients near the End of Life. Gynecologic Oncology, 125, S39. https://doi.org/10.1016/j.ygyno.2011.12.090

[13] Kumar, P., Wright, A.A., Hatfield, L.A., Temel, J.S. and Keating, N.L. (2017) Family Perspectives on Hospice Care Experiences of Patients with Cancer. Journal of Clinical Oncology, 35, 432-439. https://doi.org/10.1200/JCO.2016.68.9257

[14] Rochigneux, P., Raoul, J., Beaussant, Y., Aubry, R., Goldwasser, F., Tournigand, C., et al. (2016) Use of Chemotherapy near the End of Life: What Factors Matter? Annals of Oncology, 28, 809-817.

[15] Glare, P., Virik, K., Jones, M., Hudson, M., Eychmuller, S., Simes, J., et al. (2003) A Systematic Review of Physicians' Survival Predictions in Terminally Ill Cancer Patients. BMJ, 327, 195. https://doi.org/10.1136/bmj.327.7408.195

[16] Wright, A.A., Zhang, B., Ray, A., Mack, J., Trice, E., Balboni, T., et al. (2008) Associations between End-of-Life Discussions, Patient Mental Health, Medical Care near Death, and Caregiver Bereavement Adjustment. The Journal of the American Medical Association, 300, 1665. https://doi.org/10.1001/jama.300.14.1665

[17] Mack, J.W., Cronin, A., Keating, N.L., Taback, N., Huskamp, H.A., Malin, J.L., et al. (2012) Associations between End-of-Life Discussion Characteristics and Care Received near Death: A Prospective Cohort Study. Journal of Clinical Oncology, 30, 4387-4395. https://doi.org/10.1200/JCO.2012.43.6055

[18] Hanker, L.C., Loibl, S., Burchardi, N., Pfisterer, J., Meier, W., Pujade-Lauraine, E., et 
al. (2012) The Impact of Second to Sixth Line Therapy on Survival of Relapsed Ovarian Cancer after Primary Taxane/Platinum-Based Therapy. Annals of Oncology, 23, 2605-2612. https://doi.org/10.1093/annonc/mds203

[19] Roncolato, F., Joly, F., O'Connell, R., Lanceley, A., Hilpert, F., Buizen, L., et al. (2017) Reducing Uncertainty: Predictors of Stopping Chemotherapy Early and Shortened Survival Time in Platinum Resistant/Refractory Ovarian Cancer-The GCIG Symptom Benefit Study. Oncologist, 22, 1117-1124.

https://doi.org/10.1634/theoncologist.2017-0047

[20] Roncolato, F., Berton-Rigaud, D., O’Connell, R., Lanceley, A. and Sehouli, J. (2018) Validation of the Modified Glasgow Prognostic Score (mGPS) in Recurrent Ovarian Cancer (ROC)-Analysis of Patients Enrolled in the GCIG Symptom Benefit Study (SBS). Gynecologic Oncology, 148, 36-41.

https://doi.org/10.1016/j.ygyno.2017.10.019

[21] Wilson, M.K., Pujade-Lauraine, E., Aoki, D., Mirza, M.R., Lorusso, D., Oza, A.M., et al. (2016) 5th Ovarian Cancer Consensus Conference of the Gynecologic Cancer InterGroup: Recurrent Disease. Annals of Oncology, 28, 727-732. 